\title{
An mGlu 5 -Positive Allosteric Modulator Rescues the Neuroplasticity Deficits in a Genetic Model of NMDA Receptor Hypofunction in Schizophrenia
}

\author{
Darrick T Balu*,1,2, Yan Li', Shunsuke Takagi ${ }^{2,3}$, Kendall Taylor Presti', Teniel S Ramikie', Jerri M Rook ${ }^{4,5}$, \\ Carrie K Jones ${ }^{4,5}$, Craig W Lindsley ${ }^{4,5}$, P Jeffrey Conn ${ }^{4,5}$, Vadim Y Bolshakov' and Joseph T Coyle ${ }^{1,2}$ \\ 'Department of Psychiatry, Harvard Medical School, Boston, MA, USA; ${ }^{2}$ Laboratory for Psychiatric and Molecular Neuroscience, McLean Hospital, \\ Belmont, MA, USA; ${ }^{3}$ Department of Psychiatry and Behavioral Sciences, Graduate School of Medical and Dental Sciences, Tokyo Medical and \\ Dental University, Tokyo, Japan; ${ }^{4}$ Department of Pharmacology, Vanderbilt University Medical Center, Nashville, TN, USA; ${ }^{5}$ Vanderbilt Center for \\ Neuroscience Drug Discovery, Vanderbilt University Medical Center, Nashville, TN, USA
}

\begin{abstract}
There is substantial evidence that NMDA receptor (NMDAR) hypofunction contributes to the pathophysiology of schizophrenia (SCZ). A recent large-scale genome-wide association study identified serine racemase (SR), the enzyme that produces the NMDAR co-agonist D-serine, as a risk gene for SCZ. Serine racemase knockout (SR - / -) mice, which lack D-serine, exhibit many of the neurochemical and behavioral abnormalities observed in SCZ. Metabotropic glutamate receptor 5 ( $\mathrm{mGlu}_{5}$ )-positive allosteric modulators (PAMs) are currently being developed to treat cognitive dysfunction. We used in vitro electrophysiology to determine whether the mGlu 5 PAM VU040955। directly enhances NMDAR function in hippocampal slices from adult male SR - / - mice. We administered VU040955 I systemically for 5 days to adult male wild-type C57BL/6 animals to determine the optimal dose to test in SR - / - mice. We used western blot analyses and trace-fear conditioning to determine whether 5 days of VU040955 I treatment could reverse the neuroplasticity and learning deficits, respectively, in SR - I - mice. We show that VU040955 I enhances NMDAR function and rescues long-term potentiation in hippocampal slices obtained from SR - I - mice. Systemic treatment with VU040955 I ( 0 and 30 mg/kg) to wild-type mice causes a dose-dependent increase in the Akt/GS3K $\alpha / \beta$ signaling pathway, which is reduced in SR - / - mice and in SCZ. Furthermore, the administration of VU040955 I to SR - / - mice reverses their deficits in several neuroplasticity signaling pathways and improves their contextual fear memory. These results support positive allosteric modulation of $\mathrm{mGlu}_{5}$, particularly with $\mathrm{V} \cup 040955 \mathrm{I}$, as a viable mechanism to reverse the deficits in NMDAR function, synaptic plasticity, and memory that are known to be impaired in SCZ.

Neuropsychopharmacology (2016) 4I, 2052-206I; doi:I0.1038/npp.20I6.2; published online 3 February 2016
\end{abstract}

\section{INTRODUCTION}

There is substantial evidence that hypofunction of the $N$-methyl-D-aspartate receptor (NMDAR) is a core pathophysiological mechanism underlying schizophrenia (SCZ) (Balu and Coyle, 2011b). Recent findings from genome-wide association and exome-sequencing studies of persons diagnosed with SCZ have implicated genes encoding proteins involved in glutamatergic neurotransmission and the postsynaptic density (Fromer et al, 2014; Kirov et al, 2012; Purcell et al, 2014), including the enzyme serine racemase (SR) (Schizophrenia Working Group of the Psychiatric Genomics C, 2014). SR is responsible for the synthesis of the NMDAR co-agonist D-serine, which is concentrated in

* Correspondence: Dr DT Balu, Laboratory for Psychiatric and Molecular Neuroscience, McLean Hospital, I 15 Mill Street, Belmont, MA 02478, USA, Tel: +617 855 2329, Fax: +617 855 2705, E-mail: dbalu@mclean.harvard.edu

Received 15 October 2015; revised I December 2015; accepted 2 January 2016; accepted article preview online 7 January 2016 corticolimbic regions of the brain. Mice lacking SR (SR - / - ) exhibit many of the neuropathologic features observed in SCZ. SR - / - mice have enlarged lateral ventricles, reduced corticohippocampal volume, and perturbations in neuronal dendritic morphology in the cortex and hippocampus (Balu and Coyle, 2012; Balu et al, 2013; Puhl et al, 2015). These morphological changes are paralleled by diminished microRNA-132 expression, reduced Akt/mammalian target of rapamycin (mTOR) signaling, and decreased Arc expression (Balu and Coyle, 2014; Balu et al, 2013). Behaviorally, SR - / - mice display cognitive impairments with regards to spatial and contextual memory, as well as memory for the order of events (Balu et al, 2013; Basu et al, 2009; DeVito et al, 2011). Furthermore, SR - / - mice recapitulate the anhedonic symptoms associated with SCZ, as they show a blunted reward response to cocaine in an intracranial selfstimulation paradigm (Puhl et al, 2015).

The metabotropic glutamate receptor subtype $5\left(\mathrm{mGlu}_{5}\right)$ is expressed widely throughout the brain and is enriched in corticolimbic circuits that are important for memory and 
affect (Herman et al, 2012). It is found primarily in the postsynaptic compartment of excitatory and inhibitory neurons, although it is also found in astrocytes (Biber et al, 1999; Herman et al, 2012). Selective $\mathrm{mGlu}_{5}$ receptor ligands have been the subject of interest for reversing the NMDAR deficits associated with SCZ (Herman et al, 2012). It is well known that $\mathrm{mGlu}_{5}$ can enhance NMDAR function through its physical interaction with the NMDAR in the postsynaptic density. This enhancement is facilitated by adaptor proteins, such as Homer and Shank, and is independent of $G_{\alpha q}$ signaling (Gao et al, 2013). $\mathrm{mGlu}_{5}$ is currently a leading target for novel therapeutics to treat SCZ and cognitive disorders, particularly with the development of subtypespecific positive allosteric modulators (PAMs) (Nickols and Conn, 2014). PAMs are unique, in that unlike traditional agonists, they do not directly activate the receptor, but rather augment signaling in the presence of an endogenous agonist. This class of compounds has advantages over traditional agonists because they do not cause receptor internalization and have a safer side-effect profile.

We have previously demonstrated that chronic administration of D-serine in adulthood normalizes the electrophysiological, neurochemical, and cognitive deficits in SR-/- mice (Balu et al, 2013). A meta-analysis of 26 double-blind placebo-controlled clinical trials reported that glycine modulatory site (GMS) agonists, including D-serine, significantly improved positive, negative, and cognitive symptoms in patients with SCZ, who were receiving concurrent antipsychotic medications (Tsai and Lin, 2010). However, due to the poor pharmacokinetics and brain penetrance, as well as potential nephrotoxicity, there are several concerns about the utility of D-serine as a clinically useful medication for SCZ (Balu and Coyle, 2015). Therefore, we were interested in determining whether the recently developed, potent, and selective mGlu $_{5}$ PAM VU0409551 (Rook et al, 2015) could reverse the neuroplasticity and learning deficits in $\mathrm{SR}-/-$ mice.

\section{MATERIALS AND METHODS}

\section{Animals}

SR - / - mice (Basu et al, 2009) were generated as previously described. $\mathrm{SR} \pm$ sires and dams were bred to produce wild-type (WT) and SR - /- offspring. Adult male mice (3-5 months old) were used for all the experiments. Animals were housed in groups of four in polycarbonate cages and maintained on a $12: 12$-h light/dark cycle in a temperature $\left(22^{\circ} \mathrm{C}\right)$ - and humidity-controlled vivarium. Animals were given access to food and water ad libitum. All animal procedures were approved by the McLean Hospital Institutional Animal Care and Use Committee.

\section{Drugs}

VU0409551 was synthesized as previously described (Rook et al, 2015). Mice received once daily, intraperitoneal (i.p.) injections of vehicle (20\% hydroxypropyl $\beta$-cyclodextran (BCD); CDT Inc., Cat \#: THPB-p) or VU0409551 for 5 days at a volume of $10 \mathrm{ml} / \mathrm{kg}$. Twenty percent $\mathrm{BCD}$ was dissolved in sterile water $24 \mathrm{~h}$ before the formulation of VU0409551. VU0409551 was added to the vehicle and stirred for $\sim 5 \mathrm{~min}$, and then hand-sonicated for $1 \mathrm{~min}$ using a microtip attachment. The drug was then subjected to sonication at $40^{\circ} \mathrm{C}$ in a mechanical ultrasonic cleaner (Fisher Scientific) for $60 \mathrm{~min}$, or until all the large particles were in solution. A new solution of VU0409551 was made each day immediately before injections. For the in vivo pharmacokinetic and dose-finding experiments, WT mice $(n=5-6 /$ dose $)$ received vehicle or VU0409551 (10 and $30 \mathrm{mg} / \mathrm{kg})$. For the SR - / - mice reversal studies, WT mice received vehicle and SR-/- mice received either vehicle or VU0409551 $(30 \mathrm{mg} / \mathrm{kg})$. All mice were killed $2 \mathrm{~h}$ after the last injection on day 5.

\section{Electrophysiology}

A stock solution of VU0409551 was dissolved in dimethyl sulfoxide (Fisher Scientific) at a concentration of $30 \mathrm{mM}$. Working aliquots were stored at $-20^{\circ} \mathrm{C}$ until use in experiments. This dose was chosen based on previous in vitro hippocampal slice electrophysiology (Rook et al, 2015). Coronal hippocampal slices ( $400 \mu \mathrm{m}$ in thickness) were prepared from adult SR $-/$ - or WT mice (littermates) with a vibratome. Slices were continuously perfused in solution containing (in $\mathrm{mM}$ ) $125 \mathrm{NaCl}, 2.5 \mathrm{KCl}, 2.5 \mathrm{CaCl}_{2}$, $1.0 \mathrm{MgSO}_{4}, 1.25 \mathrm{NaH}_{2} \mathrm{PO}_{4}, 26 \mathrm{NaHCO}_{3}, 10$ glucose, and 0.05 picrotoxin, and equilibrated with $95 \% \mathrm{O}_{2}$ and $5 \% \mathrm{CO}_{2}(\mathrm{pH}$ 7.3-7.4) at $22^{\circ} \mathrm{C}$. Field excitatory postsynaptic potentials (fEPSPs) were recorded in the stratum radiatum of the CA1 region. Synaptic responses were evoked at $0.033 \mathrm{~Hz}$ by stimulation of Schaffer collaterals with a concentric stimulation electrode (Balu et al, 2013). Long-term potentiation (LTP) of synaptic transmission was induced by one 1-s train of $100-\mathrm{Hz}$ stimulation after recording of baseline fEPSPs. In these experiments, we measured the initial slope of the fEPSPs' rising phase. The magnitude of LTP was estimated during a 5-min window $45 \mathrm{~min}$ after it was induced. NMDAR-mediated field EPSPs (NMDAR-fEPSPs) were recorded in low external $\mathrm{Mg}^{2+}\left(0-0.1 \mathrm{mM} \mathrm{Mg}^{2+}\right.$ in the ACSF) in the presence of picrotoxin $(50 \mu \mathrm{M})$ and the AMPAR antagonist, 2,3-dihydroxy-6-nitro-7-sulfamoyl-benzo[f] quinoxaline-2,3-dione (NBQX; $10 \mu \mathrm{M}$; (Papouin et al, 2012)). Under these conditions the fEPSPs were mediated by NMDARs, which was confirmed by their sensitivity to a specific NMDAR antagonist $(50 \mu \mathrm{M}$ D-AP5, Figure 2a). To assay the effect of SR ablation on (S)-3,5-dihydroxyphenylglycine (DHPG)-induced mGluR-LTD, fEPSPs were recorded at CA3-CA1 synapses in slices from control and mutant mice. After obtaining a stable baseline, DHPG $(75 \mu \mathrm{M})$ was applied for $10 \mathrm{~min}$. This resulted in significant depression of synaptic responses (DHPG-induced LTD). The average of fEPSP amplitudes during the last $6 \mathrm{~min}$ of recordings was used for statistical analysis.

\section{In vivo VU0409551 Pharmacokinetic Analysis}

The animals were killed and decapitated, and the brains were removed, thoroughly washed in cold phosphate-buffered saline, and cortex frozen on dry ice; trunk blood was collected into EDTA-treated tubes and centrifuged (1700 r.p.m., $5 \mathrm{~min}$ ) to provide plasma samples. Samples were shipped on dry ice to Vanderbilt University 
for analysis by HPLC-MS/MS (Supplementary Materials and Methods).

\section{Western Blot Analysis}

Immunoblotting was performed as previously described (Balu and Coyle, 2011a). Primary antibodies are listed in Supplementary Table S1. Chemiluminescent values of the protein of interest were divided by its corresponding $\beta$-actin chemiluminescent values. The ratio of each WT sample was divided by the average of all the WT sample values in each gel and multiplied by 100 . The average of the normalized WT values from each gel was $100 \% \pm$ SEM. The mutant values were normalized to WT values (\%WT) collected in parallel from the same gel. The normalized values were then averaged and used for statistical analysis.

\section{Trace Fear Conditioning}

One cohort of WT mice received 5 days of either vehicle $(n=8)$ or VU0409551 (30 mg/kg, $n=8)$ and was subjected to a trace fear-conditioning paradigm during the last 3 days of treatment. Another cohort of WT ( $n=19$; vehicle), SR - / ( $n=13$; vehicle), and SR - / - mice treated with VU0409551 ( $30 \mathrm{mg} / \mathrm{kg} ; n=12$ ) was subjected to a trace fear-conditioning paradigm during the last 3 days of treatment. Injections were given $2 \mathrm{~h}$ before behavioral testing. On day 1 , each conditioning session consisted of a 3-min acclimation period followed by seven trials of the following structure: a 20 -s tone (conditioned stimulus; CS) at $75 \mathrm{~dB}$ followed by a 20 -s trace period followed by a foot-shock (duration $2 \mathrm{~s}$, amplitude $0.7 \mathrm{~mA}$; unconditioned stimulus, US). Trials were roughly 4 min apart. On day 2, mice were placed in the same conditioning chambers as on day 1 and freezing behavior was measured for $8 \mathrm{~min}$. On day 3 , mice were placed in chambers with different contextual cues, including a smooth chamber floor, a peppermint odor (peppermint extract diluted $1: 1 \mathrm{~K}$ ), and a roof insert to distinguish the testing environment from the conditioning environment. The protocol from day 1 was repeated without the foot-shock. The house light in the chamber was illuminated during all sessions. All testing was performed using The Near Infrared Fear Conditioning System (Med Associates, Inc.; St. Albans, VT). Freezing behavior was quantified using VideoFreeze software.

\section{Statistical Analyses}

Two-way ANOVA (genotype $\times$ drug) with Newman-Keuls multiple comparisons test was used to compare groups for the electrophysiology results in Figure 1c. Two-way repeated measures ANOVA (genotype $\times$ time) with Bonferroni's multiple comparisons test was used to compare groups for the electrophysiology results in Figure 2e. Unpaired Student's $t$-test was used to analyze the electrophysiological data in Figure 2f. Two-way repeated measures ANOVA was used to analyze the data obtained from day 1 of the trace fearconditioning experiments. Unpaired $t$-tests were used to analyze the contextual and cue freezing data obtained from the WT mice after chronic VU0409551 treatment. Type I (fixed effect) one-way ANOVAs were used to analyze western blot and fear-conditioning (context and cue) results
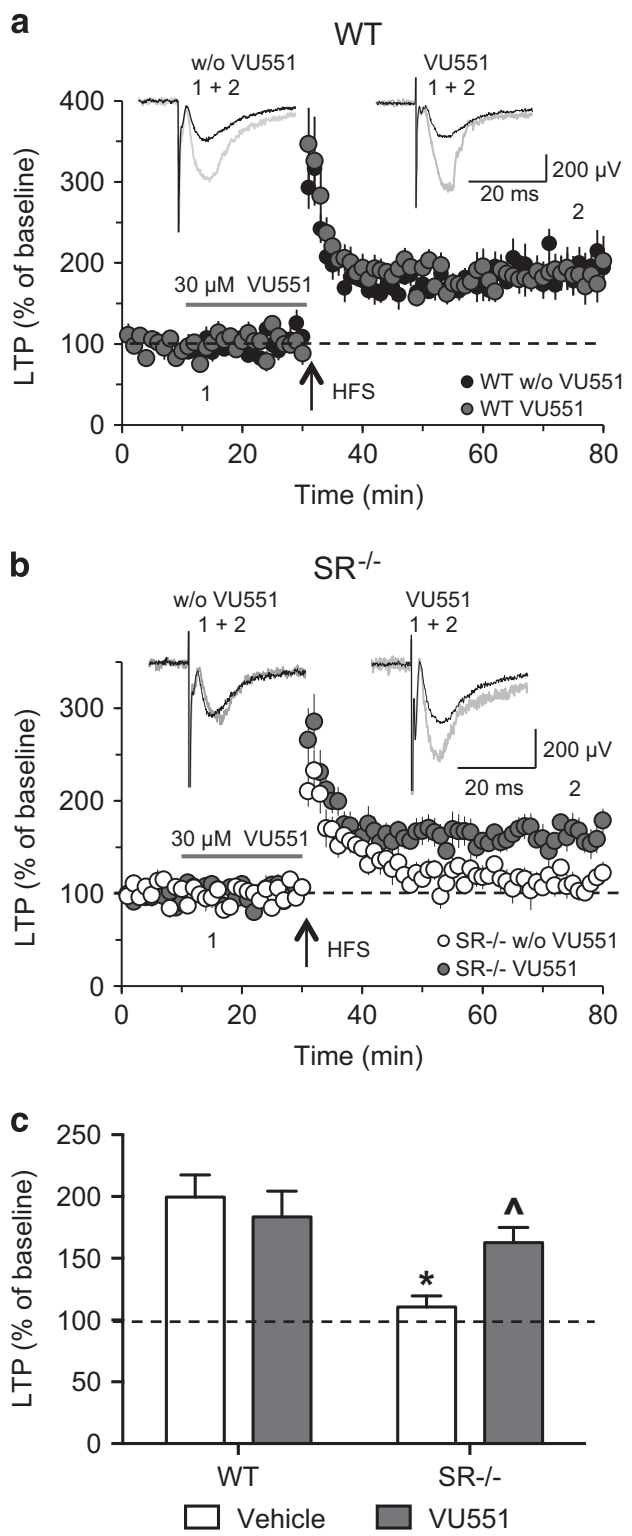

Figure I VU040955 I rescues synaptic plasticity deficits in the hippocampus of SR - / - mice. (a) Averaged graphs showing results of LTP experiments performed in slices from WT mice under control conditions (solid black circles, $n=6$ slices from two WT mice) and after VU55I treatment (red circles, $n=7$ slices from three WT mice). Insets show averages of 40 fEPSPs before (black trace) and 10 fEPSPs (thick gray trace) 45 min after LTP induction. (b) Results of LTP experiments in untreated slices (open circles, $n=7$ slices from four SR - / - mice) or slices treated with $30 \mu \mathrm{m}$ VU040955I (VU55I; red filled circles, $n=9$ slices from five $\mathrm{SR}-1-$ mice). Insets show averages of 60 fEPSPs (black trace) before and I0 fEPSPs (gray trace) 45 min after LTP induction under both conditions (with or without the treatment of slices with VU55I). (c) Summary of LTP results for the four experimental groups (white bars, vehicle; red bars, VU55I). Data are presented as the mean \pm SEM. Significant two-way ANOVA results were followed up with Newman-Keuls multiple comparisons tests. Asterisk (*) indicates significant difference from the WT vehicle group $(P<0.05)$ and ${ }^{\wedge}$ indicates significant difference from the $\mathrm{SR}-/$ - vehicle group. A full color version of this figure is available at the Neuropsychopharmacology journal online.

following chronic VU0409551 treatment. Significant oneway ANOVA results were followed up by Newman-Keuls multiple comparison test. Values of $P<0.05$ were considered statistically significant. 


\section{RESULTS}

\section{VU0409551 Restores NMDA Receptor Function in SR - / - Mice}

SR - / - mice display NMDAR hypofunction in several brain regions, including the cortex (Basu et al, 2009), hippocampus
(Balu et al, 2013; Basu et al, 2009), and amygdala (Li et al, 2013), due to the lack of D-serine availability. Specifically, SR - / - mice have reduced LTP at the juvenile Schaffer collateral CA3-CA1 synapse (Basu et al, 2009) and at the adult medial perforant path-dentate gyrus (DG) synapse (Balu et al, 2013). To test whether synaptic plasticity deficits in the hippocampus of

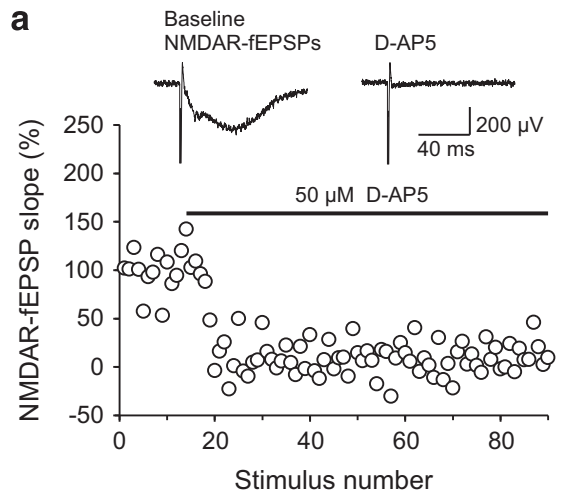

b
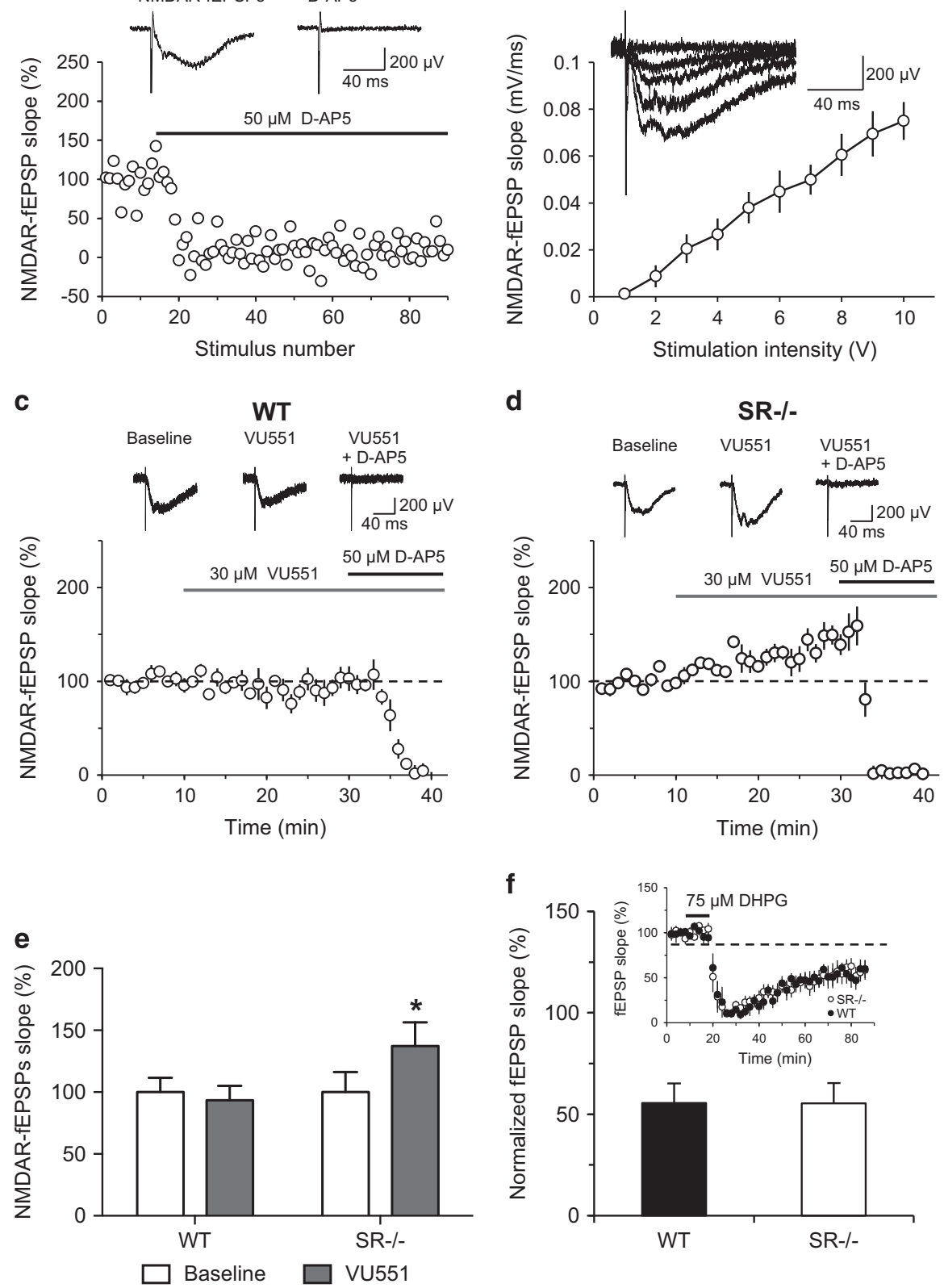

Figure 2 VU040955 I potentiates NMDAR-fEPSPs in SR - / - mice, but not WT mice. (a) Recorded NMDAR-fEPSPs were abolished by the specific NMDAR antagonist D-AP5 $(50 \mu \mathrm{M})$. Insets show averages 15 NMDAR-fEPSPs during baseline recording (left) and I5 NMDAR-fEPSPs 5 min after the application of NMDAR antagonist (right). (b) The synaptic input-output curve for NMDAR-fEPSPs obtained at CA3-CAI synapses by presynaptic stimuli of increasing intensity in slices from WT mice ( $n=5$ slices). Inset shows averaged NMDAR-fEPSPs ( 10 traces) at stimulation intensities of I, 3, 4, 5 and $7 \mathrm{~V}$. (c) Insets show averages of 20 NMDAR-fEPSPs before (left), I 0 fEPSPs 15 min after (middle) the application of VU55I, and I0 NMDAR-fEPSPs 5 min after (right) the addition of D-AP5 $(50 \mu M)$. Summary of VU55I (30 $\mu$ M) tests in WT mice ( $n=5$ slices from two WT mice). (d) Insets show averages of 20 NMDAR-fEPSPs before (left), I0 NMDAR-fEPSPs $15 \mathrm{~min}$ after (middle) the application of VU040955। (VU55I), and 10 NMDAR-fEPSPs 5 min after (right) the addition of the NMDAR antagonist D-AP5 $(50 \mu M)$. Summary of VU55I (30 $\mu$ M) tests in SR $-/-$ mice $(n=7$ slices from three SR - I - mice). (e) Summary of the results for all four groups is shown in C and d; white bars, baseline; red bars, VU55I. Significant two-way repeated measures ANOVA results were followed up by Bonferroni's multiple comparisons test to compare groups. (f) Time course of DHPG-induced depression of fEPSPs at CA3-CAI synapses in slices from WT ( $n=4$ slices from three mice; black bar) and SR - / - mice ( $n=5$ slices from two mice; white bar). Summary of the experiments is shown in inset (averages of fEPSP amplitudes during the last 6 min of recordings). Data are presented as the mean \pm SEM. Asterisk (*) indicates significant difference from the SR $-1-$ baseline group $(P<0.05)$. A full color version of this figure is available at the Neuropsychopharmacology journal online. 
SR - / - mice could be reversed by VU0409551, a highly selective $\mathrm{mGlu}_{5}$ PAM, we performed LTP experiments in WT and SR - / - mice. We show that the magnitude of LTP at the CA3CA1 synapse was significantly reduced in untreated hippocampal slices from adult SR - / - mice (Figure 1a-c; two-way ANOVA; genotype: $\mathrm{F}_{1,25}=12.70, P<0.005$; drug: $\mathrm{F}_{1,25}=1.38, P=0.25$; interaction: $\mathrm{F}_{1,25}=4.90, p<0.05$; Newman-Keuls multiple comparisons test). The magnitude of LTP in slices from SR - / mice was $110.8 \pm 8.9 \%$ of baseline value, compared with $199.6 \pm 17.6 \%$ of baseline value in slices from WT mice. Treatment with VU0409551 $(30 \mu \mathrm{M})$ for $20 \mathrm{~min}$ during the recording of baseline fEPSPs significantly enhanced fEPSPs and rescued the deficits of synaptic plasticity in $\mathrm{SR}-/-$ mice $(162.9 \pm 12.2 \%$; Newman-Keuls multiple comparisons test). The same treatment in slices from control mice did not affect the magnitude of LTP $(183.7 \pm 20.9 \%)$ compared with untreated slices (Figure 1a and c; Newman-Keuls multiple comparisons test). As mentioned above, in untreated slices from SR - / mice, the fEPSP magnitude after the delivery of LTP-inducing stimulation was not different from the baseline amplitude value (paired $t$-test, $t_{6}=1.38, P=0.22 v s$ baseline fEPSPs; Figure $1 \mathrm{~b}$ and c). The treatment with VU0409551 did not affect the amplitude of baseline fEPSPs (paired $t$-test; WT: $t_{7}=0.28, P=0.79$; SR - / $-: t_{9}=2.06, P=0.07$; fEPSPs during the first 5 min $v s$ fEPSPs during the last $5 \mathrm{~min}$ of the 20-min-long application of VU0409551; $n=8$ slices from three WT mice and $n=10$ slices from five SR - / - mice), suggesting that VU0409551 did not alter AMPAR-mediated synaptic responses at the CA3-CA1 hippocampal synapses.

To test whether VU0409551 could affect NMDAR-mediated synaptic responses, we assayed the effect of VU0409551 $(30 \mu \mathrm{M})$ on NMDAR-fEPSPs. First, we demonstrated that the recorded fEPSPs were mediated by NMDARs by showing they were blocked with the NMDAR antagonist AP5 (Figure 2a). We also plotted the synaptic input-output curves for NMDARfEPSPs obtained at CA3-CA1 synapses by presynaptic stimuli of increasing intensity in slices from WT mice (Figure 2b). We found that the application of $30 \mu \mathrm{m}$ VU0409551 for $20 \mathrm{~min}$ did not potentiate NMDAR-fEPSPs (baseline fEPSPs $v s$ the last 5-min recording of NMDAR-fEPSPs during a 20-min-long application of VU0409551) in slices from WT mice (Figure 2c and e: two-way repeated measures ANOVA genotype: $\mathrm{F}_{1,10}=0.96, P=0.35$; time: $\mathrm{F}_{1,10}=5.22, P=0.046$; interaction: $\left.\mathrm{F}_{1,10}=10.62, p<0.01\right)$, in agreement with recent findings in WT rats (Rook et al, 2015). However, application of VU0409551 resulted in significant potentiation of NMDARfEPSPs in SR - / - mice (Figure 2d and e: Bonferroni's multiple comparisons test). As shown in Figure $2 \mathrm{c}$ and $\mathrm{d}$, the recorded NMDAR-fEPSPs in both WT and SR $-/-$ mice were completely abolished by the NMDAR antagonist (D-AP5, $50 \mu \mathrm{M})$, confirming that the recorded fEPSPs were indeed mediated by NMDARs. Finally, we compared the magnitude of DHPG-induced LTD in slices from WT and SR $-/-$ mice to determine whether there was a potential difference in type I mGluR-mediated signaling between genotypes. We found no difference between the groups (Figure 2f; unpaired $t$-test; $\left.t_{7}=0.01, P=0.99\right)$.
In vivo Characterization of VU0409551 in Wild-Type Mice

As VU0409551 was able to restore NMDAR function in $\mathrm{SR}-/$ - mice in vitro, we next wanted to see whether this compound could rescue other neuroplasticity deficits in $\mathrm{SR}-/$ - mice in vivo. Rook et al (2015) demonstrated a favorable pharmacokinetic profile and brain penetration for VU0409551 in the rat. We first characterized the pharmacokinetic profile of VU0409551 in C57BL/6 mice following subchronic (5 days) intraperitoneal administration. As shown in Supplementary Table S2, there was a dosedependent increase in the concentration of VU0409551 in the plasma and cerebral cortex, with the $30 \mathrm{mg} / \mathrm{kg}$ dose producing concentrations $2.4 \times$ and $5 \times$ higher than the $10 \mathrm{mg} / \mathrm{kg}$ dose, respectively.

After determining that adequate concentrations of VU0409551 were achieved in the brain following chronic dosing, we next tested whether these doses elicited any changes in Akt/GS3K $\alpha / \beta$ signaling in the hippocampus and prefrontal cortex (PFC) of WT mice. We chose this signaling pathway because it is impaired in the hippocampus of SR - / - mice (Balu et al, 2013). Furthermore, group I mGlu receptor agonists and older-generation $\mathrm{mGlu}_{5}$ PAMs have been shown to increase Akt phosphorylation (Doria et al, 2015; Hou and Klann, 2004). VU0409551 dose-dependently increased pAkt (Figure 3a; $\mathrm{F}_{2,13}=5.9, P<0.05$ ) and $\mathrm{pGS} 3 \mathrm{~K} \alpha / \beta$ (Figure $3 \mathrm{~b}$; $\left.\alpha: \mathrm{F}_{2,13}=5.6, P<0.05 ; \beta: \mathrm{F}_{2,13}=3.8, P<0.05\right)$ in the hippocampus, but only the $30 \mathrm{mg} / \mathrm{kg}$ dose achieved significance. VU0409551 had no effect on the phosphorylation status of p-mTOR (Figure $3 c ; F_{2,13}=1.34, P=0.29$ ) or TrkB (Figure 3d; $\left.\mathrm{F}_{2,13}=0.01, P=0.99\right)$. A similar pattern was observed in the PFC (Supplementary Figure Sla-d), except the $30 \mathrm{mg} / \mathrm{kg}$ dose of VU0409551 significantly increased only pAkt (Supplementary Figure S1a; $F_{2,25}=3.5, P=0.05$ ). Interestingly, VU0409551 had no effect on extracellular regulated kinase 1/2 phosphorylation (pERK1, $\mathrm{F}_{2,13}=0.07, \quad P>0.05 ; \quad$ pERK2, $\left.\mathrm{F}_{2,13}=0.42, P>0.05\right)$. This is similar to what was observed in normal rats in vivo (data not shown, PJC), even though VU0409551 was able to stimulate ERK signaling in HEK293 cells stably expressing rat mGlu5 in vitro (Rook et al, 2015).

\section{VU0409551 Reverses Neurochemical and Learning Deficits in SR - / - Mice}

Given that the $30 \mathrm{mg} / \mathrm{kg}$ dose of VU0409551 produced the most robust changes, we examined whether it could reverse the neurochemical abnormalities in the hippocampus of SR - / - mice. Indeed, VU0409551 reversed the pTrkB (Figure $4 \mathrm{a} ; \mathrm{F}_{2,23}=5.2, \quad P<0.05$ ) and pAkt (Figure 4b; Ser473, $\mathrm{F}_{2,24}=4.5, P<0.05 ;$ Thr308, $\mathrm{F}_{2,24}=3.7, P<0.05$; pAkt1 Ser473, $\left.F_{2,24}=4.3, P<0.05\right)$ deficits, as well as the downstream deficits in pGS3K $\alpha / \beta$ (Figure $4 \mathrm{c} ; \alpha: \mathrm{F}_{2,25}=5.0$, $P<0.05 ; \beta: \mathrm{F}_{2,24}=5.3, P<0.05$ ) and $\mathrm{p}-\mathrm{mTOR}$ (Figure $4 \mathrm{~d}$; $\left.\mathrm{F}_{2,24}=8.1, \quad P<0.005\right)$ in $\mathrm{SR}-/-$ mice. Furthermore, VU0409551 rescued the deficit in the phosphorylation state of protein kinase A (PKA; Figure $4 \mathrm{e} ; \mathrm{F}_{2,23}=4.8, P<0.05$ ), which is dependent, in part, upon $\mathrm{Ca}^{2+}$ influx through NMDARs. The activity-regulated cytoskeletal-associated protein (Arc) is an immediate early gene that is positively regulated by NMDAR activity. Arc protein levels were lower 


\section{Hippocampus}

a

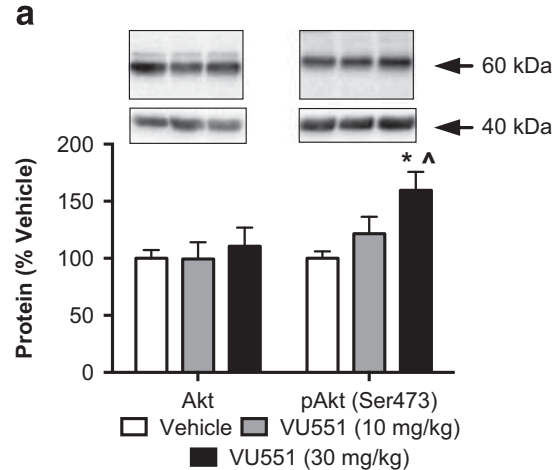

C



b

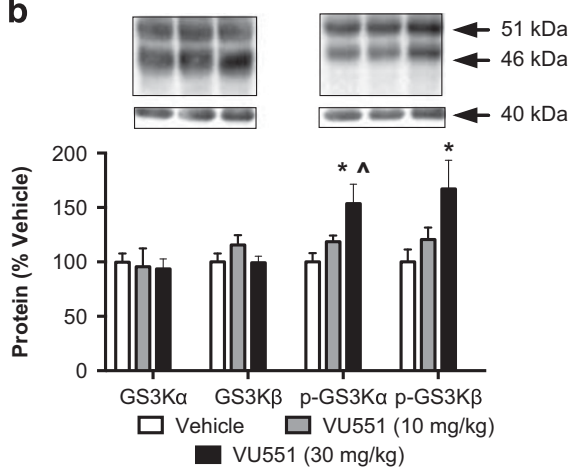

d

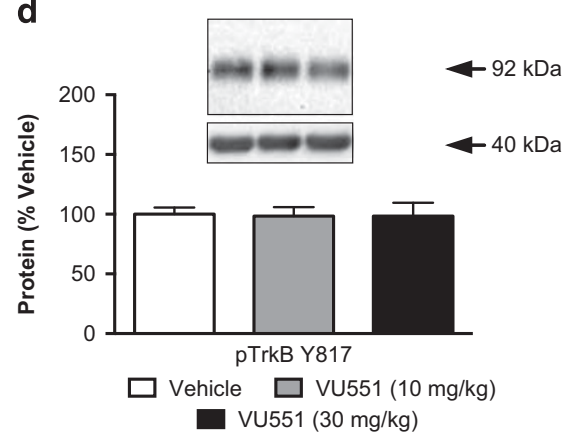

Figure 3 VU040955I dose-dependently enhances Akt/GS3K signaling in the hippocampus of WT mice. WT mice received 5 days of either vehicle (white bars, $n=5$ ) or VU040955 I (VU55 I: $10 \mathrm{mg} / \mathrm{kg}$, gray bars, $n=6 ; 30 \mathrm{mg} / \mathrm{kg}$, black bars, $n=5$ ) and were killed $2 \mathrm{~h}$ after the last injection. Protein levels of (a) Akt and p-Akt, Ser 473, (b) glycogen synthase kinase 3 (GS3K) $\alpha / \beta$ and p-GS3K $\alpha / \beta(\alpha=5 \mathrm{l}$ kDa, $\beta=46 \mathrm{kDa}),(\mathrm{c}) \mathrm{p}-\mathrm{mTOR} / \mathrm{mTOR}$, and (d) pTrkB Y8I7 in the hippocampus. Values are expressed as the optical density (OD) normalized to WT values (\%WT). Each western blot image includes a representative band of the protein of interest and $\beta$-actin (4I kDa) from each of the experimental groups: vehicle, VU55I (I $0 \mathrm{mg} / \mathrm{kg}$ ), VU55 I (30 mg/kg), respectively. Significant oneway ANOVA results were followed up by Newman-Keuls multiple comparison test. Asterisk $\left(^{*}\right)$ indicates significant differences from the vehicle group $(P<0.05)$ and ${ }^{\wedge}$ indicates difference from $10 \mathrm{mg} / \mathrm{kg}$ VU55I. All values represent the mean \pm SEM.

in the hippocampus of $\mathrm{SR}-/$ - mice, which was restored to WT levels by VU0409551 (Figure $4 \mathrm{f}, \mathrm{F}_{2,25}=8.4, P<0.005$ ).

Emotional learning and memory, as well as contextual processing are impaired in patients with SCZ (Hall et al, 2007; Maren et al, 2013). Classical Pavlovian fear conditioning is one of the most powerful and widely used models for studying emotional memory and associative learning in rodents (LeDoux, 2000). We utilized a trace fearconditioning assay (temporal gap between the tone and the shock) to determine whether VU0409551 could reverse the contextual memory deficits of SR - / - mice. We first found that in WT mice, VU0409551 affected neither the acquisition (Figure 5a; two-way repeated measures ANOVA; drug: $\mathrm{F}_{1,23}=0.74, P=0.40$; tone: $\mathrm{F}_{6,138}=34.3, P<0.0001$; interaction: $\left.\mathrm{F}_{6,138}=0.30, P=0.93\right)$ nor the expression of fear to the context (Figure $5 \mathrm{~b} ; t_{21}=1.5, P=0.15$ ) and the cue (Figure $5 \mathrm{c} ; t_{21}=1.39$, $P=0.18)$. The amount of freezing between $\mathrm{SR}-/-$ mice treated with vehicle or VU551 also did not differ from WT mice during conditioning on day 1 (Figure 5d; two-way repeated measures ANOVA; genotype: $F_{2,42}=0.16, P=0.86$; tone: $\mathrm{F}_{6,252}=41.8, P<0.0001$; interaction: $\left.\mathrm{F}_{2,252}=1.43, P=0.15\right)$. We found that vehicle-treated SR $-/$ - mice froze less in the conditioning context and VU0409551 was able to rescue this deficit in contextual fear memory in SR $-/-$ mice (Figure 5e; $\left.\mathrm{F}_{2,41}=3.68, P<0.05\right)$. We did not observe deficits in cued fear conditioning in SR - / - mice and VU0409551 had no effect on freezing behavior (Figure 5f; $\mathrm{F}_{2,28}=0.70, P=0.51$; average freezing during the first three 20 -s tone presentations).

\section{DISCUSSION}

The $\mathrm{mGlu}_{5}$ has garnered recent attention as a tractable drug target for several brain disorders with cognitive symptoms, including SCZ (Herman et al, 2012). Thus, we examined whether the newly developed mGlu $_{5}$ PAM VU0409551 would be able to restore the neuroplasticity deficits in SR - / - mice, a genetic NMDAR hypofunction model relevant to SCZ (Schizophrenia Working Group of the Psychiatric Genomics C, 2014). We found that VU0409551 enhanced hippocampal NMDAR function and restored LTP in SR - / - mice. Furthermore, subchronic VU0409551 rescued the neurochemical abnormalities and learning deficits of SR - / - mice.

Genetic (Basu et al, 2009) and pharmacologic (Le Bail et al, 2015) studies have shown that D-serine is the primary NMDAR co-agonist at adult hippocampal CA3-CA1 synapses and that $\mathrm{SR}-1$ - mice display NMDAR hypofunction in this region. We demonstrate here that VU0409551 rescues deficits in NMDAR-mediated synaptic responses in the hippocampus of SR - / - mice. Furthermore, VU0409551 enhanced LTP at the CA3-CA1 synapse in SR-/- mice. 



$\square$ SR-/- (VU-551)

d
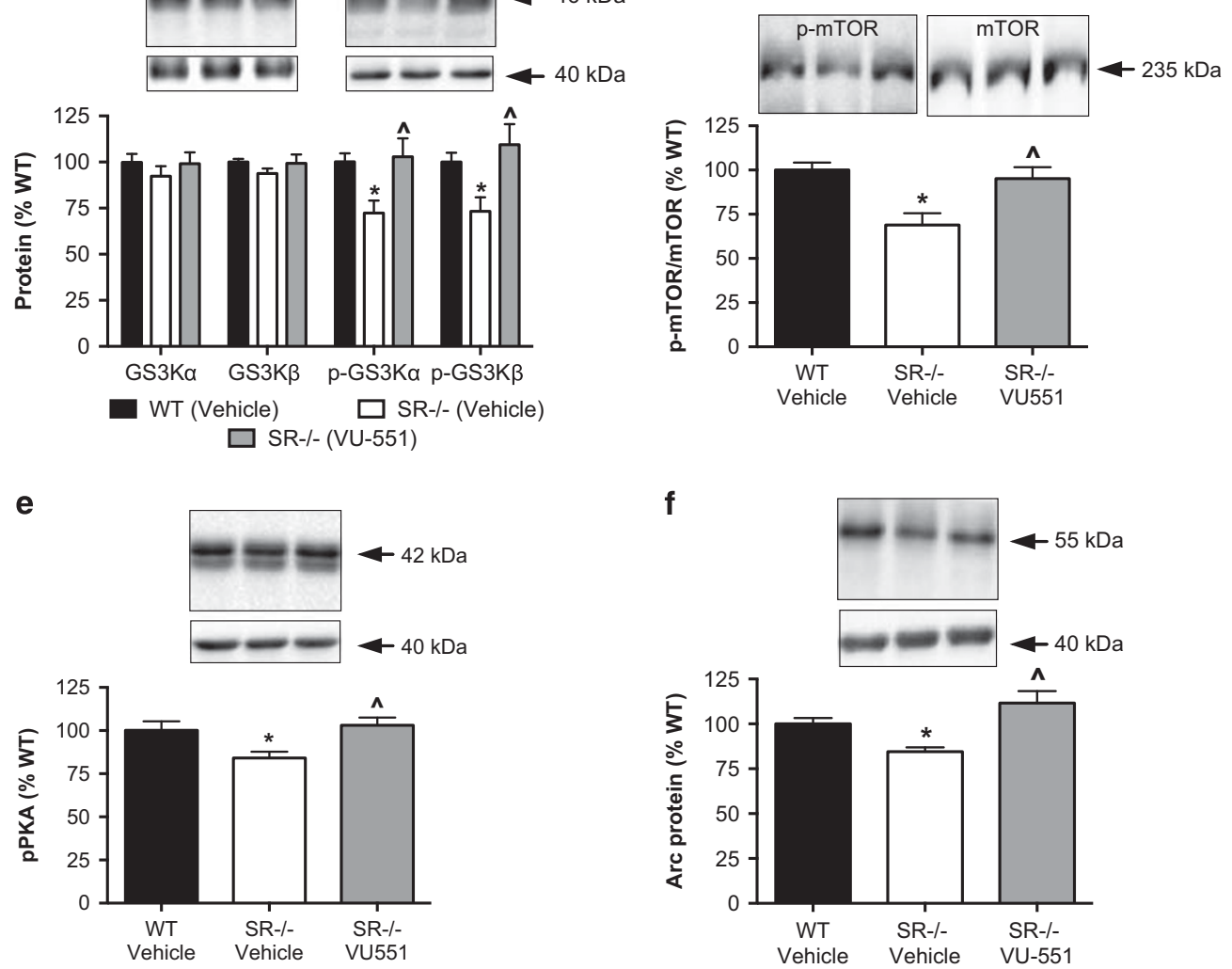

Figure 4 Chronic VU040955 I treatment rescues the hippocampal neurochemical deficits in SR $-/-$ mice. WT $(n=10)$ and SR $-/-(n=7-8)$ mice received 5 days of either vehicle or VU040955। (VU55I; $30 \mathrm{mg} / \mathrm{kg}$; i.p.) and were killed $2 \mathrm{~h}$ after the last injection. Protein levels of (a) phosphorylated tropomysin receptor kinase B (pTrkB) Tyr8 I7, (b) Akt, p-Akt Ser473, and p-Akt Thr308, Akt I, p-AktI Ser473, (c) glycogen synthase kinase 3 (GS3K) $\alpha / \beta$ and p-GS3K $\alpha / \beta(\alpha=5 \mathrm{I}$ kDa, $\beta=46 \mathrm{kDa})$, (d) p-mTOR Ser2448/mTOR, (e) p-protein kinase A (PKA), and (f) activity-regulated cytoskeleton-associated protein (Arc) were measured in the hippocampus of WT mice (black bars), SR - I - mice (vehicle; white bars), or SR - I - mice treated with VU55I (gray bars) as the optical density normalized to WT values (\%WT). Each western blot image includes a representative band of the protein of interest and $\beta$-actin (4I kDa) from each of the experimental groups: WT (vehicle), SR - I - 55I (vehicle), SR - I - (VU55I), respectively. Asterisk (*) indicates significant difference from the WT vehicle group $(P<0.05)$ and ${ }^{\wedge}$ indicates significant difference from the SR - / - vehicle group. Significant one-way ANOVA results were followed up by Newman-Keuls multiple comparison test. All values represent the mean \pm SEM.

These results are especially interesting in light of the unique properties of VU0409551 relative to previously reported $\mathrm{mGlu}_{5}$ PAMs. It is well established that $\mathrm{mGlu}_{5}$, through its physical interaction with the NMDAR in the postsynaptic density, can potentiate NMDAR activity. This potentiation is facilitated by adaptor proteins, such as Homer and Shank, and is independent of $\mathrm{G}_{\alpha \mathrm{q}}$ signaling ( $\mathrm{Gao}$ et al, 2013). However, VU0409551 displays a unique 'stimulus bias' and potentiates coupling of $\mathrm{mGlu}_{5}$ to $\mathrm{G}_{\alpha q}$, but does not directly potentiate $\mathrm{mGlu}_{5}$ modulation of NMDAR currents in hippocampus of WT animals (Rook et al, 2015). Consistent with this finding in rats, we found that VU0409551 did not enhance NMDAR fEPSPs in hippocampal slices from WT mice. Similarly, VU0409551 was also found not to augment LTP or potentiate NMDAR currents in the hippocampus of normal rats (Rook et al, 2015). These findings raise the possibility that constitutively reduced NMDAR activity leads to changes in the composition of receptors, scaffolding, and/ 

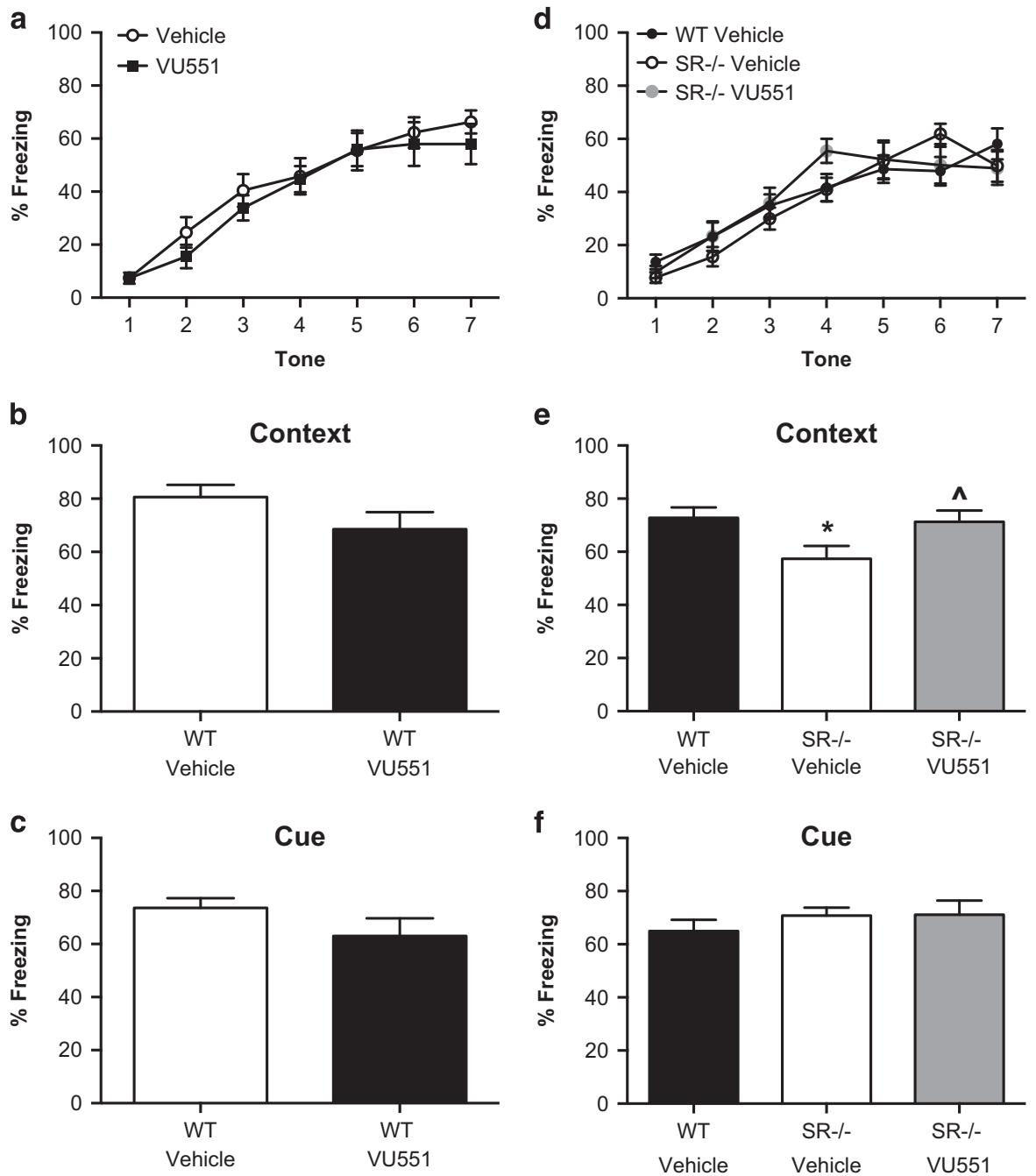

Figure 5 Chronic VU040955 I treatment improves memory in SR - I - mice. WT mice received 5 days of either vehicle (white; $n=8$ ) or VU040955 I (VU55।; $30 \mathrm{mg} / \mathrm{kg}$, black, $n=8$ ) and were subjected to a trace fear-conditioning paradigm during the last 3 days of treatment. Injections were given $2 \mathrm{~h}$ before behavioral testing. (a) The amount of freezing during each of the seven tone presentations was measured for each group. (b) The average time animals froze during the first 4 min of being placed in the chamber on day 2. (c) The average time animals froze during the first three tone presentations on day 3 . WT (vehicle, black, $n=19), S R-1-$ (vehicle, white, $n=13$ ), and SR - I- mice treated with VU55I (30 mg/kg, gray, $n=12)$ were subjected to a trace fearconditioning paradigm during the last 3 days of treatment. Injections were given $2 \mathrm{~h}$ before behavioral testing. (d) The amount of freezing during each of the seven tone presentations was measured for each group. (e) The average time animals froze during the first 4 min of being placed in the chamber on day 2. ( $f$ ) The average time animals froze during the first three tone presentations on day 3. Significant one-way ANOVA results were followed up by Newman-Keuls multiple comparison test. Asterisk (*) indicates significant difference from the WT vehicle group $(P<0.05)$ and ${ }^{\wedge}$ indicates significant difference from the $\mathrm{SR}-1-$ vehicle group. All values represent the mean \pm SEM.

or signaling molecules in the postsynaptic density (Balu and Coyle, 2011a), such that VU0409551 can augment NMDAR function in this genetic background. Similar findings were recently reported in studies of another $\mathrm{mGlu}_{5}$ PAM 3-cyano$\mathrm{N}$-(1,3-diphenyl-1H-pyrazol-5-yl) benzamide (CDPPB), which was shown to rescue NMDAR electrophysiological deficits in a Shank2-/- genetic mouse model of autism, without affecting the same measures in WT littermates (Won et al, 2012). However, it is also possible that VU0409551 restores deficits in NMDAR-mediated signaling in SR - / mice by a mechanism that does not require direct modulation of NMDAR currents. Interestingly, recent studies have shown that $\mathrm{mGlu}_{5}$ activation can prime CA3-CA1 synapses for induction of LTP by inducing release of endocannabinoids from CA1 pyramidal cells that act on neighboring inhibitory terminals to depress neurotransmission at inhibitory GABAergic synapses (iLTD) onto the pyramidal cells (Chevaleyre and Castillo, 2003, 2004; Younts et al, 2013; Xu et al, 2014). This disinhibition induced by $\mathrm{mGlu}_{5}$ can facilitate neurotransmission and induction of NMDAR-dependent LTP at glutamatergic synapses and does not require direct modulation of NMDAR currents, but is dependent on $\mathrm{mGlu}_{5}$ activation of $\mathrm{G}_{\alpha \mathrm{q}}$ and phospholipase $\mathrm{C}$ (Chevaleyre and Castillo, 2003, 2004). Our results demonstrate the critical importance of testing novel compounds for desired therapeutic action in disease-relevant models, where disorder-relevant perturbation(s) in brain physiology have been established. 
There are several mechanisms by which subchronic administration of VU0409551 could facilitate the complete reversal of Akt/GS3K/mTOR signaling deficits in SR - / mice. Akt is activated by binding to phospholipids at the plasma membrane and subsequent phosphorylation at Thr308, by protein dependent kinase 1 (PDK1) in a phosphoinositide 3 kinase (PI3K)-dependent manner, (4) and Ser473 by the mTORC2 complex (formerly known as PDK2). It has been shown that CDPPB increases pAkt in vitro (Doria et al, 2013) and in vivo (Doria et al, 2015). The activation of Akt by group I mGlu receptors involves the GTPase PI3K enhancer-long (PIKE-L), which couples PI3K to group I mGlu receptors via the adaptor protein Homer (Rong et al, 2003). Stimulation of NMDAR activity or TrkB by VU0409551 treatment could also activate this pathway. Interestingly, VU0409551 did not augment the phosphorylation states of TrkB and mTOR in the hippocampus of WT mice. This suggests that the composition of certain adaptor proteins at the membrane and/or intracellular cascades is altered by the constitutive NMDAR hypofunction of SR - / mice. Finally, VU0409551 was shown to potentiate $G_{\alpha q^{-}}$ mediated calcium release in the presence of glutamate in a HEK293A in vitro cell culture system (Rook et al, 2015). However, it is unclear whether the effect of VU0409551 on calcium release holds true in vivo. Future work will be needed to determine the mechanism(s) that are responsible for the ability of VU0409551 to normalize Akt signaling in the hippocampus of SR $-/-$ mice.

Mouse genetic and pharmacological studies in rats demonstrate the importance of $\mathrm{mGlu}_{5}$ in cognition (Herman et al, 2012). Emotional learning and memory and contextual processing are impaired in patients with SCZ (Hall et al, 2007; Maren et al, 2013). In contrast to delay fear conditioning, trace fear conditioning places a temporal gap between the tone (CS) and the shock (US). The insertion of this trace interval during CS-US presentation alters the brain circuitry recruited for fear learning (Raybuck and Lattal, 2014) and makes the association more difficult than delay conditioning (Kinney et al, 2002). This paradigm also engages working memory and attention circuits, which are perturbed in SCZ (Young and Geyer, 2015). The expression of contextual fear memory following trace fear conditioning is dependent on NMDARs in the dorsal hippocampus (Misane et al, 2005; Quinn et al, 2005). We found that VU0409551 was able to restore the contextual memory impairments of adult SR $-/-$ mice in a trace fear-conditioning paradigm. We believe that the memory-enhancing effects of VU0409551 in SR - / - mice are due to the ability of this compound to reverse the hypofunction of their hippocampal NMDARs. However, $\mathrm{mGlu}_{5} \mathrm{~s}$ are also highly expressed in the medial prefrontal and anterior cingulate cortices, areas that are important for trace fear learning (Raybuck and Lattal, 2014). Future studies will determine in which particular brain regions $\mathrm{mGlu}_{5}$ enhances NMDAR function and where stimulation is important for reversing the learning deficits in SR - / - mice. It should be noted that VU0409551 was found to enhance acquisition of contextual fear conditioning in normal rats (Rook et al, 2015). The lack of effect in WT mice could be due to several factors, including species differences, the type of fear conditioning used (contextual $v$ s trace), and/or a ceiling effect due to the high level of freezing in vehicle-treated WT mice.
In sum, VU0409551 was as effective as D-serine in normalizing NMDAR function, as well as reversing the neurochemical and learning deficits in SR $-/-$ mice. These findings are of considerable importance because they demonstrate that a primary deficit in NMDAR function, in this case due to a lack of co-agonist, can be overcome by targeting a different receptor. Positive allosteric modulation of $\mathrm{mGlu}_{5}$ not only augments NMDAR function but also stimulates the Akt pathway, which is impaired in $\mathrm{SR}-/-$ mice and is also genetically linked to SCZ (Emamian, 2012). VU0409551 has a more favorable safety profile compared with other mGlu $_{5}$ PAMs, as well as a more favorable pharmacokinetic and pharmacodynamic profile than endogenous GMS agonists, such as D-serine and glycine. Therefore, this study highlights the potential use of this compound to treat disorders, such as SCZ, in which NMDAR hypofunction is a contributing etiological factor. Importantly, VU0409551 ameliorates those processes in the SR - / - mouse that are linked to negative symptoms and cognitive impairments in SCZ, the very ones that are associated with persistent disability and are unresponsive to current antipsychotic medications (Strassnig et al, 2015).

\section{FUNDING AND DISCLOSURE}

This research was supported by A Phyllis \& Jerome Lyle Rappaport Mental Health Research Scholars Award, 1K99MH099252-01A1, and 5R00MH099252-04 (DTB); R01MH05190 and P50MH0G0450 (JTC); R01MH062646, R01MH074953, and R01NS031373 (PJC); and U54MH084659 (CWL). JTC has served as a consultant to Novartis, Forum Pharmaceuticals, and Abbvie in the last 2 years. A patent owned by Massachusetts General Hospital for the use of D-serine as a treatment for serious mental illness could yield royalties for Dr Coyle. CWL, PJC, and CKJ have received research support from Johnson and Johnson, Bristol Myers Squibb, and Astrazeneca, and are inventors on patents that protect multiple classes of $\mathrm{mGlu}_{5}$ PAMs. The remaining authors declare no conflict of interest.

\section{ACKNOWLEDGMENTS}

We thank Alexandra Berg for animal colony maintenance and genotyping. We thank Dr Uwe Rudolph for the generous use of his behavioral equipment and software.

\section{REFERENCES}

Balu DT, Coyle JT (2011a). Glutamate receptor composition of the post-synaptic density is altered in genetic mouse models of NMDA receptor hypo- and hyperfunction. Brain Res 1392: 1-7.

Balu DT, Coyle JT (2011b). Neuroplasticity signaling pathways linked to the pathophysiology of schizophrenia. Neurosci Biobehav Rev 35: 848-870.

Balu DT, Coyle JT (2012). Neuronal D-serine regulates dendritic architecture in the somatosensory cortex. Neurosci Lett 517: 77-81.

Balu DT, Coyle JT (2014). Chronic D-serine reverses arc expression and partially rescues dendritic abnormalities in a mouse model of NMDA receptor hypofunction. Neurochem Int 75C: 76-78. 
Balu DT, Coyle JT (2015). The NMDA receptor 'glycine modulatory site' in schizophrenia: D-serine, glycine, and beyond. Curr Opin Pharmacol 20C: 109-115.

Balu DT, Li Y, Puhl MD, Benneyworth MA, Basu AC, Takagi S et al (2013). Multiple risk pathways for schizophrenia converge in serine racemase knockout mice, a mouse model of NMDA receptor hypofunction. Proc Natl Acad Sci USA 110: E2400-E2409.

Basu AC, Tsai GE, Ma CL, Ehmsen JT, Mustafa AK, Han L et al (2009). Targeted disruption of serine racemase affects glutamatergic neurotransmission and behavior. Mol Psychiatry 14: 719-727.

Biber K, Laurie DJ, Berthele A, Sommer B, Tolle TR, Gebicke-Harter PJ et al (1999). Expression and signaling of group I metabotropic glutamate receptors in astrocytes and microglia. J Neurochem 72: 1671-1680.

Chevaleyre V, Castillo PE (2003). Heterosynaptic LTD of hippocampal GABAergic synapses: a novel role of endocannabinoids in regulating excitability. Neuron 38: 461-472.

Chevaleyre V, Castillo PE (2004). Endocannabinoid-mediated metaplasticity in the hippocampus. Neuron 43: 871-881.

DeVito LM, Balu DT, Kanter BR, Lykken C, Basu AC, Coyle JT et al (2011). Serine racemase deletion disrupts memory for order and alters cortical dendritic morphology. Genes Brain Behav 10: 210-222.

Doria JG, de Souza JM, Andrade JN, Rodrigues HA, Guimaraes IM, Carvalho TG et al (2015). The mGluR5 positive allosteric modulator, $\mathrm{CDPPB}$, ameliorates pathology and phenotypic signs of a mouse model of Huntington's disease. Neurobiol Dis 73: 163-173.

Doria JG, Silva FR, de Souza JM, Vieira LB, Carvalho TG, Reis HJ et al (2013). Metabotropic glutamate receptor 5 positive allosteric modulators are neuroprotective in a mouse model of Huntington's disease. Br J Pharmacol 169: 909-921.

Emamian ES (2012). AKT/GSK3 signaling pathway and schizophrenia. Front Mol Neurosci 5: 33.

Fromer M, Pocklington AJ, Kavanagh DH, Williams HJ, Dwyer S, Gormley $\mathrm{P}$ et al (2014). De novo mutations in schizophrenia implicate synaptic networks. Nature 506: 179-184.

Gao C, Tronson NC, Radulovic J (2013). Modulation of behavior by scaffolding proteins of the post-synaptic density. Neurobiol Learn Mem 105: 3-12.

Hall J, Harris JM, McKirdy JW, Johnstone EC, Lawrie SM (2007). Emotional memory in schizophrenia. Neuropsychologia 45: $1152-1159$.

Herman EJ, Bubser M, Conn PJ, Jones CK (2012). Metabotropic glutamate receptors for new treatments in schizophrenia. Handb Exp Pharmacol 213: 297-365.

Hou L, Klann E (2004). Activation of the phosphoinositide 3kinase-Akt-mammalian target of rapamycin signaling pathway is required for metabotropic glutamate receptor-dependent longterm depression. J Neurosci 24: 6352-6361.

Kinney JW, Starosta G, Holmes A, Wrenn CC, Yang RJ, Harris AP et al (2002). Deficits in trace cued fear conditioning in galanintreated rats and galanin-overexpressing transgenic mice. Learn Mem 9: 178-190.

Kirov G, Pocklington AJ, Holmans P, Ivanov D, Ikeda M, Ruderfer D et al (2012). De novo CNV analysis implicates specific abnormalities of postsynaptic signalling complexes in the pathogenesis of schizophrenia. Mol Psychiatry 17: 142-153.

Le Bail M, Martineau M, Sacchi S, Yatsenko N, Radzishevsky I, Conrod S et al (2015). Identity of the NMDA receptor coagonist is synapse specific and developmentally regulated in the hippocampus. Proc Natl Acad Sci USA 112: E204-E213.
LeDoux JE (2000). Emotion circuits in the brain. Annu Rev Neurosci 23: $155-184$.

Li Y, Sacchi S, Pollegioni L, Basu AC, Coyle JT, Bolshakov VY (2013). Identity of endogenous NMDAR glycine site agonist in amygdala is determined by synaptic activity level. Nat Commun 4: 1760 .

Maren S, Phan KL, Liberzon I (2013). The contextual brain: implications for fear conditioning, extinction and psychopathology. Nat Rev Neurosci 14: 417-428.

Misane I, Tovote P, Meyer M, Spiess J, Ogren SO, Stiedl O (2005). Time-dependent involvement of the dorsal hippocampus in trace fear conditioning in mice. Hippocampus 15: 418-426.

Nickols HH, Conn PJ (2014). Development of allosteric modulators of GPCRs for treatment of CNS disorders. Neurobiol Dis 61: 55-71.

Papouin T, Ladepeche L, Ruel J, Sacchi S, Labasque M, Hanini M et al (2012). Synaptic and extrasynaptic NMDA receptors are gated by different endogenous coagonists. Cell 150: 633-646.

Puhl MD, Mintzopoulos D, Jensen JE, Gillis TE, Konopaske GT, Kaufman MJ et al (2015). In vivo magnetic resonance studies reveal neuroanatomical and neurochemical abnormalities in the serine racemase knockout mouse model of schizophrenia. Neurobiol Dis 73: 269-274.

Purcell SM, Moran JL, Fromer M, Ruderfer D, Solovieff N, Roussos P et al (2014). A polygenic burden of rare disruptive mutations in schizophrenia. Nature 506: 185-190.

Quinn JJ, Loya F, Ma QD, Fanselow MS (2005). Dorsal hippocampus NMDA receptors differentially mediate trace and contextual fear conditioning. Hippocampus 15: 665-674.

Raybuck JD, Lattal KM (2014). Bridging the interval: theory and neurobiology of trace conditioning. Behav Process 101: 103-111.

Rong R, Ahn JY, Huang H, Nagata E, Kalman D, Kapp JA et al (2003). PI3 kinase enhancer-Homer complex couples mGluRI to PI3 kinase, preventing neuronal apoptosis. Nat Neurosci 6: 1153-1161.

Rook JM, Xiang Z, Lv X, Ghoshal A, Dickerson JW, Bridges TM et al (2015). Biased mGlu5-positive allosteric modulators provide in vivo efficacy without potentiating mGlu5 modulation of NMDAR currents. Neuron 86: 1029-1040.

Schizophrenia Working Group of the Psychiatric Genomics C (2014). Biological insights from 108 schizophrenia-associated genetic loci. Nature 511: 421-427.

Strassnig MT, Raykov T, O'Gorman C, Bowie CR, Sabbag S, Durand D et al (2015). Determinants of different aspects of everyday outcome in schizophrenia: the roles of negative symptoms, cognition, and functional capacity. Schizophr Res 165: 76-82.

Tsai GE, Lin PY (2010). Strategies to enhance N-methyl-D-aspartate receptor-mediated neurotransmission in schizophrenia, a critical review and meta-analysis. Curr Pharm Des 16: 522-537.

Won H, Lee HR, Gee HY, Mah W, Kim JI, Lee J et al (2012). Autistic-like social behaviour in Shank2-mutant mice improved by restoring NMDA receptor function. Nature 486: 261-265.

$\mathrm{Xu}$ J, Antion MD, Nomura T, Kraniotis S, Zhu Y, Contractor A (2014). Hippocampal metaplasticity is required for the formation of temporal associative memories. J Neurosci 34: 16762-16773.

Young JW, Geyer MA (2015). Developing treatments for cognitive deficits in schizophrenia: the challenge of translation. $J$ Psychopharmacol 29: 178-196.

Younts TJ, Chevaleyre V, Castillo PE (2013). CA1 pyramidal cell theta-burst firing triggers endocannabinoid-mediated long-term depression at both somatic and dendritic inhibitory synapses. J Neurosci 33: 13743-13757.

Supplementary Information accompanies the paper on the Neuropsychopharmacology website (http://www.nature.com/npp) 